\title{
Facilitators and Barriers for Implementation of Shared Decision Making: A Review
}

\author{
Pavan Kumar Narapaka ${ }^{1}$, Kalpana Katikala², Varun Raj Ponnala ${ }^{3}$, \\ Sudha Madhavi Penumaka ${ }^{4}$, Fedrick Virupapuram ${ }^{5}$
}

\begin{abstract}
${ }^{1,2,3}$ M Pharmacy, Department of Pharmacy Practice, National Institute of Pharmaceutical Education and Research, Export Promotion Industrial Park (EPIP), Zandhaha Road, NH 322, Hajipur, Bihar - 844102

${ }^{4}$ M.S Pharma, Department of Biotechnology, National Institute of Pharmaceutical Education and Research, Export Promotion Industrial Park (EPIP), Zandhaha Road, NH 322, Hajipur, Bihar - 844102

${ }^{5}$ M.S Pharma, Department of Pharmacology and Toxicology, National Institute of Pharmaceutical Education and Research, Export Promotion Industrial Park (EPIP), Zandhaha Road, NH 322, Hajipur, Bihar - 844102
\end{abstract}

Corresponding Author: Pavan Kumar Narapaka

\begin{abstract}
Shared decision-making is patient-centered Care that involves patients and health care professionals to decide treatment for patient condition mutually. Healthcare professionals have not widely adopted shared decisionmaking because some barriers/facilitators stop healthcare professionals from implementing shared decision-making in the same way some barriers/facilitators are preventing patients from involving in shared decision-making. Many studies have explained barriers/facilitators that stop patients/healthcare professionals from applying in SDM individually. The objective of the study is to examine the patient-related and healthcare professional's related barriers / facilitators to implementing SDM.
\end{abstract}

Keywords: SDM, Shared decision-making, barriers, facilitators

\section{INTRODUCTION}

Shared decision-making is a standard method where using the best available evidence, clinicians and patients make decisions together, helps to select the best course of action for them, patients are encouraged to think about the appropriate screening, treatment, or management options and the likely benefits and harms of each. ${ }^{[1]}$ The concept of SDM is seen as a critical patient-centered component of Care and describes the importance of the patient's physician Relationship in health outcomes. [2] Shared decision-making depends on establishing a solid therapeutic relationship to exchange knowledge and assist patients in deliberating and sharing their interests and concerns during the decision-making process. ${ }^{[3]}$ Care and kindness were once often the only "treatment" open to physicians. Over time, developments in medical research have created new options that have unwittingly distanced physicians from their patients, although they also enhance results. Patients and their families are frequently excluded from critical conversations and left feeling in the dark to solve these forms of issues that have been brought into therapy through shared decision-making. ${ }^{[4]}$ Shared decision-making provides a systematic way to integrate facts into medical decision-making and patient beliefs and expectations. This process will promote discussions that lead to betterinformed decisions aligned with what matters most to patients. Suppose they do not entirely understand their current health condition, treatment options, and the possible side effects of each treatment choice. The following phases are included in shared decision-making. A decision may require more than one visit a) Identify a clear decision point b) Provide information about the clinical problem and options at the 
Pavan Kumar Narapaka et.al. Facilitators and barriers for implementation of shared decision making: a review.

decision point. C) Elicit the patient perspective d) Guide the patient toward a final decision. e) Assess how comfortable the patient is with his or her decision. ${ }^{[5,6]}$ Shared decision-making has earned wide range of acclaim for its clinical advantages and positive effects on patient involvement. It will rely on effective patient outreach to adopt a practical and patient-centered shared decision-making approach. ${ }^{[6]}$ In shared decision-making (SDM), which is at the heart of patient-centered treatment, there has recently been an explosion of interest and research. SDM is a two-way mechanism in which both the patient and the clinician share evidence and the responsibility for decision-making. ${ }^{[7]}$

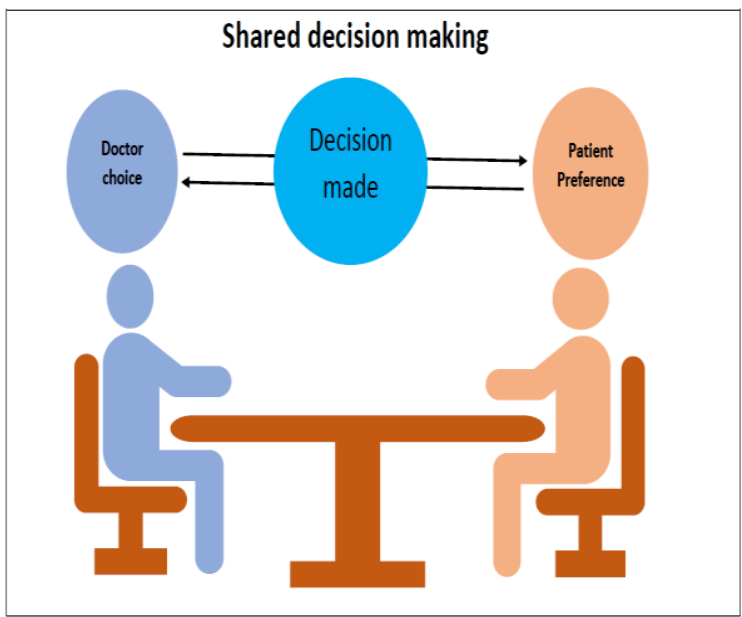

Steps for implementation of shared decision making

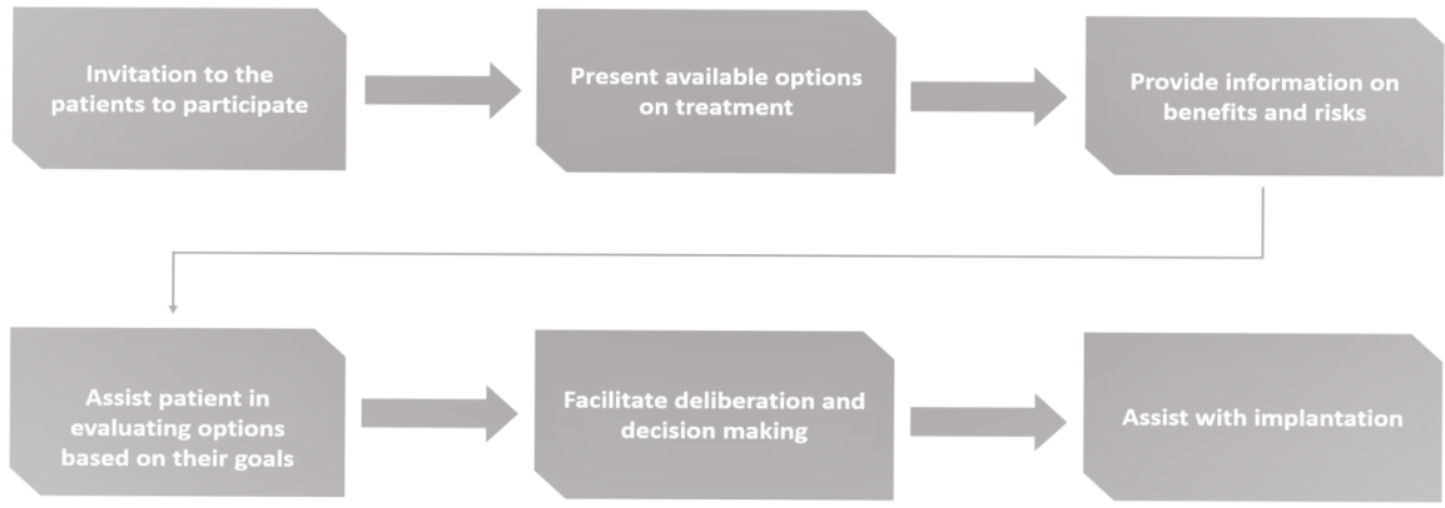

Patients perceived barriers and facilitators for implementation of shared decision making

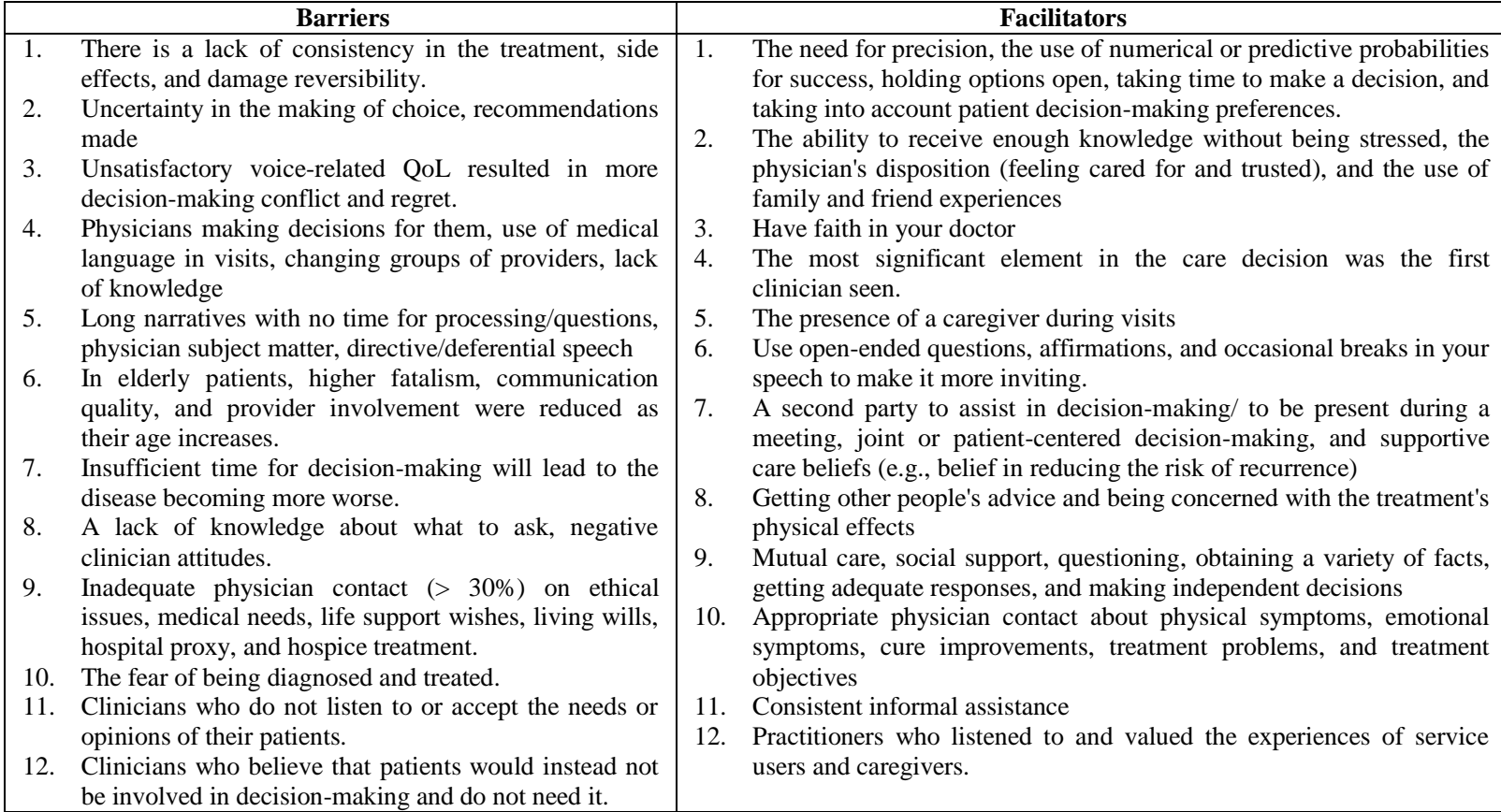



review.

\section{Physician perceived barriers and facilitators for implementation of Shared decision making}

\begin{tabular}{|c|c|c|}
\hline Barriers & Facilitators & Barriers and facilitators \\
\hline $\begin{array}{l}\text { 1. Unfamiliarity with the situation } \\
\text { 2. Ignorance } \\
\text { 3. Lack of time for patients to engage in the SDM process } \\
\text { due to clinicians' busy schedules. } \\
\text { 4. a scarcity of capital } \\
\text { 5. Clinicians who conclude that patients would instead } \\
\text { not be involved in decision-making and do not need it. } \\
\text { 6. The patient didn't know what he was doing } \\
\text { 7. Insufficient information } \\
\text { 8. Unawareness }\end{array}$ & $\begin{array}{l}\text { 1. A feeling of anticipation } \\
\text { 2. Working with the patient } \\
\text { 3. provide adequate time for } \\
\text { SDM implementation }\end{array}$ & $\begin{array}{ll}\text { 1. Inquiring about the patient's role } \\
\text { 2. } \\
\text { 2. jo time decision-making } \\
\text { 3. insufficient capital } \\
\text { 4. inability to obtain surveillance } \\
\text { 5. patients sharing liability } \\
6 . \quad \text { patient's expectations } \\
\text { 7. incapacity to judge } \\
8 . \quad \text { incompatibility } \\
9 . \quad \text { use-complexity } \\
\text { 10. inability to be seen } \\
\text { 11. inability to get paid } \\
\text { 12. motivational deficits } \\
\text { 13. cost-effective }\end{array}$ \\
\hline
\end{tabular}

\section{Some of the common barriers and facilitators for the implementation of shared decision making}

\begin{tabular}{|c|c|}
\hline \multicolumn{2}{|l|}{ Environmental Factors } \\
\hline Organizational factor & Healthcare system factors \\
\hline The passing of time (bar and fac) & Regulatory and policy framework (bar and fac) \\
\hline $\begin{array}{l}\text { 2. There are far too many physicians involved in patient care } \\
\text { (bar) }\end{array}$ & $\begin{array}{l}\text { 2. SDM communication skills should be integrated into medical } \\
\text { education (fac) }\end{array}$ \\
\hline Environmental conditions that aren't perfect (bar) & 3. Incentivizing providers to participate in SDM through a \\
\hline Resources are scarce (bar) & payment model (fac) \\
\hline Encouragement in the use of decision aids (bar and fac) & \\
\hline $\begin{array}{l}\text { 6. Healthcare professionals' encouragement to incorporate SDM } \\
\text { (bar and fac) }\end{array}$ & \\
\hline SDM consultations on several occasions (bar and fac) & \\
\hline SDM is triggered by an e-health record (fac) & \\
\hline SDM performance assessment and reviews (fac) & \\
\hline $\begin{array}{l}\text { 10. Non-physician staff (e.g., nurses, social workers) are involved } \\
\text { (bar and fac) }\end{array}$ & \\
\hline \multicolumn{2}{|l|}{ Patient/Family Factors } \\
\hline Patients' perceptions & Patient capacity \\
\hline The belief that "the doctor is always right" (bar) & State of health (bar and fac) \\
\hline Not able to comprehend medical knowledge (bar) & Characteristics of Patients (bar and fac) \\
\hline Asking questions is appropriate (bar and fac) & Lack of self-confidence (bar) \\
\hline Patients' participation is frowned upon by physicians (bar) & Parental participation is significant (fac) \\
\hline $\begin{array}{l}\text { Acceptance of the fact that the medical encounter involves two } \\
\text { experts (fac) }\end{array}$ & $\begin{array}{l}\text { 5. Preferences and fears are two things that people have when it } \\
\text { comes to making decisions. }\end{array}$ \\
\hline Recognizing and dealing with confusion and equipoise (fac) & Preferences for being a part of the process (bar and fac) \\
\hline Accepting the management of involvement (bar and fac) & Fear the repercussions of being labeled as complex (bar) \\
\hline In consultations, there is a lack of expectation for SDM (bar) & Fear of receiving a diagnosis and having to recognize it (bar) \\
\hline $\begin{array}{c}\text { In consultations, there is a lack of expectation for SDM (bar) } \\
\text { Relationship factors }\end{array}$ & Factors related to information provision \\
\hline \multirow{10}{*}{$\begin{array}{l}\text { 1. The relationship's consistency (bar and fac) } \\
\text { 2. Have faith in your doctor (bar and fac) } \\
\text { 3. The clinician is familiar with the patient or is unfamiliar with } \\
\text { the patient (fac and bar) } \\
\text { 4. Patients and clinicians have different personal characteristics } \\
\text { (e.g., gender, language) (bar) }\end{array}$} & Talking about the preferences of the patients (bar and fac) \\
\hline & Listening to patients' Needs and Acknowledging their Views \\
\hline & (bar and fac) \\
\hline & Checking for knowledge comprehension regularly (fac) \\
\hline & Explicitly allowing participation in SDM (bar and fac) \\
\hline & Patients aren't given clear options (bar) \\
\hline & 6. Educating patients on treatment choices and results (bar and \\
\hline & Using easy-to-understand terms (bar and fac) \\
\hline & Sharing accountability with the patient (fac) \\
\hline & Using decision support tools (fac) \\
\hline
\end{tabular}

\section{Professional characteristics}

1. Personality traits (bar and fac)

2. SDM isn't well-known (bar)

3. Make decisions in an authoritarian way (bar)

4. a decision-making style that is shared (fac)

5. Behavioral patterns (bar)

6. Expert opinion(bar)

7. Patients tend not to be active and do not need it, according to this perspective (bar)

8. Recognizing patients' desire to engage in decision-making and their obligations to do so (bar and fac)

9. Patient outcomes and the healthcare process are projected to improve as a result of SDM (fac)

10. Aspects of SDM that have been agreed upon (bar and fac)

\section{Importance of shared decision making in clinical practice:}

Patients can gain confidence in their caregivers by using shared decision-making strategies, and providers can connect and interact with their patients more effectively. ${ }^{[31]}$ According to research, patients who are given the power to make healthcare choices that match their interests report feeling more 

review.

involved in their care and having improved health outcomes, such as reduced anxiety, faster recovery, and greater adherence to treatment regimens. ${ }^{[32]}$ The use of decision aids decreased the number of patients who were passive in their care and improved patient adherence to prescribed treatments. Patients also had more information, more realistic perception of risk, and less internal tension when it came to healthcare decisions. ${ }^{[33]}$ SDM remains a valuable tool for promoting patient autonomy and satisfaction due to its positive interaction with patient outcomes. ${ }^{[34]}$ Health outcomes and the patient experience will also benefit from shared decision-making. ${ }^{[35]}$

\section{CONCLUSION}

Overall, there were strong themes in this study about the barriers and facilitators to implementing SDM in health care. These characteristics may help develop a straightforward SDM plan for clinical care, including treatments and decision aids, by considering patients' principles when making treatment decisions and maximizing training opportunities for medical professionals involved in health care delivery.

\section{Acknowledgement: None}

\section{Conflict of Interest: None}

\section{Source of Funding: None}

\section{REFERENCES}

1. Elwyn G, Laitner S, Coulter A, Walker E, Watson $\mathrm{P}$, Thomson R. Implementing shared decision making in the NHS. Bmj. 2010 Oct 14:341.

2. Covvey JR, Kamal KM, Gorse EE, Mehta Z, Dhumal T, Heidari E, Rao D, Zacker C. Barriers and facilitators to shared decisionmaking in oncology: a systematic review of the literature. Supportive Care in Cancer. 2019 May 1;27(5):1613-37.

3. Elwyn G, Frosch D, Thomson R, JosephWilliams N, Lloyd A, Kinnersley P, Cording E, Tomson D, Dodd C, Rollnick S, Edwards A. Shared decision making: a model for clinical practice. Journal of general internal medicine. 2012 Oct 1;27(10):1361-7.

4. Barry MJ, Edgman-Levitan S. Shared decision making- The pinnacle patientcentered care.

5. Grad R, Légaré F, Bell NR, Dickinson JA, Singh H, Moore AE, Kasperavicius D, Kretschmer KL. Shared decision making in preventive health care: What it is; what it is not. Canadian Family Physician. 2017 Sep 1;63(9):682-4.

6. Heath S. Three Best Practices for Shared Decision-Making in Healthcare. Patient Engagement Hit. 2017.

7. Barber SK, Ryan F, Cunningham SJ. Knowledge of, and attitudes to, shared decision-making in orthodontics in the UK. Journal of Orthodontics. 2020 Dec;47(4): 294-302.

8. Henrikson NB, Ellis WJ, Berry DL. "It's not like I can change my mind later": Reversibility and decision timing in prostate cancer treatment decision-making. Patient education and counseling. 2009 Nov 1;77(2):302-7.

9. Lally RM. In the moment: women speak about surgical treatment decision making days after a breast cancer diagnosis. In Oncology Nursing Forum 2009 Sep 1 (Vol. 36, No. 5).

10. Arora NK, Gustafson DH. Perceived helpfulness of physicians' communication behavior and breast cancer patients' level of trust over time. Journal of general internal medicine. $2009 \mathrm{Feb}$;24(2):252-5.

11. Shuman AG, Larkin K, Thomas D, Palmer FL, Fins JJ, Baxi SS, Lee N, Shah JP, Fagerlin A, Patel SG. Patient reflections on decision making for laryngeal cancer treatment. Otolaryngology-Head and Neck Surgery. 2017 Feb;156(2):299-304.

12. Lee SC, Marks EG, Sanders JM, Wiebe DJ. Elucidating patient-perceived role in "decision-making" among African Americans receiving lung cancer care through a county safety-net system. Journal of Cancer Survivorship. 2016 Feb 1;10(1): 153-63.

13. Chhabra KR, Pollak KI, Lee SJ, Back AL, Goldman RE, Tulsky JA. Physician communication styles in initial consultations for hematological cancer. Patient education and counseling. 2013 Dec 1;93(3):573-8. 
14. Shelton RC, Hillyer GC, Hershman DL, Leoce N, Bovbjerg DH, Mandelblatt JS, Kushi LH, Lamerato L, Nathanson SD, Ambrosone CB, Neugut AI. Interpersonal influences and attitudes about adjuvant therapy treatment decisions among nonmetastatic breast cancer patients: an examination of differences by age and race/ethnicity in the BQUAL study. Breast cancer research and treatment. 2013 Feb;137(3):817-28.

15. Song L, Chen RC, Bensen JT, Knafl GJ, Nielsen ME, Farnan L, Wallen EM, Mishel M, Pruthi RS, Mohler JL, Godley PA. Who makes the decision regarding the treatment of clinically localized prostate cancer-the patient or physician? Results from a population- based study. Cancer. 2013 Jan 15;119(2):421-8.

16. Pieters HC, Heilemann MV, Maliski S, Dornig K, Mentes J. Instrumental relating and treatment decision making among older women with early-stage breast cancer. InOncology nursing forum 2012 Jan 1 (Vol. 39, No. 1).

17. Graham ID, Logan J, O'Connor A, Weeks KE, Aaron S, Cranney A, Dales R, Elmslie T, Hebert P, Jolly E, Laupacis A. A qualitative study of physicians' perceptions of three decision aids. Patient education and counseling. $2003 \mathrm{Jul}$ 1;50(3):279-83.

18. Elwyn G, Edwards A, Gwyn R, Grol R. Towards a feasible model for shared decision making: focus group study with general practice registrars. Bmj. 1999 Sep 18;319(7212):753-6.

19. Ford S, Schofield T, Hope T. What are the ingredients for a successful evidence-based patient choice consultation?: A qualitative study. Social Science \& Medicine. 2003 Feb 1;56(3):589-602.

20. Keefe CW, Thompson ME, Noel MM. Medical students, clinical preventive services, and shared decision-making. Academic medicine: journal of the Association of American Medical Colleges. 2002 Nov 1;77(11):1160-1.

21. Thistlethwaite J, Van Der Vleuten C. Informed shared decision making: views and competencies of pre-registration house o. cers in hospital and general practice. Education for Primary Care. 2004 Feb $1 ; 15(1)$.

22. Charles C, Gafni A, Whelan T. Selfreported use of shared decision-making among breast cancer specialists and perceived barriers and facilitators to implementing this approach. Health Expectations. 2004 Dec;7(4):338-48.

23. Howell JW. Physicians' opinions about patient involvement in health and medical care decisions and telephone-based decision support. University of Colorado at Denver; 1999.

24. McGuire AL, McCullough LB, Weller SC, Whitney SN. Missed expectations?: physicians' views of patients' participation in medical decision-making. Medical Care. 2005 May 1;43(5):466-70.

25. Légaré F, Ratté S, Gravel K, Graham ID. Barriers and facilitators to implementing shared decision-making in clinical practice: update of a systematic review of health professionals' perceptions. Patient education and counseling. 2008 Dec 1;73(3):526-35.

26. Robertson EG, Wakefield CE, Signorelli C, Cohn RJ, Patenaude A, Foster C, Pettit T, Fardell JE. Strategies to facilitate shared decision-making about pediatric oncology clinical trial enrollment: a systematic review. Patient education and counseling. 2018 Jul 1;101(7):1157-74.

27. Scholl I, LaRussa A, Hahlweg P, Kobrin S, Elwyn G. Organizational-and system-level characteristics that influence implementation of shared decision-making and strategies to address them- a scoping review. Implementation Science. 2018 Dec; 13(1):1-22.

28. Daly RL, Bunn F, Goodman C. Shared decision-making for people living with dementia in extended care settings: a systematic review. BMJ open. 2018 Jun $1 ; 8(6)$.

29. Gondek D, Edbrooke-Childs J, Velikonja T, Chapman L, Saunders F, Hayes D, Wolpert M. Facilitators and barriers to personcentred care in child and young people mental health services: A systematic review. Clinical psychology \& psychotherapy. 2017 Jul;24(4):870-86.

30. Joseph-Williams N, Elwyn G, Edwards A. Knowledge is not power for patients: a systematic review and thematic synthesis of patient-reported barriers and facilitators to shared decision making. Patient education and counseling. 2014 Mar 1;94(3):291-309.

31. Peek ME, Gorawara-Bhat R, Quinn MT, Odoms-Young A, Wilson SC, Chin MH. Patient trust in physicians and shared 
Pavan Kumar Narapaka et.al. Facilitators and barriers for implementation of shared decision making: a review.

decision-making among African-Americans with diabetes. Health communication. 2013 Aug 1;28(6):616-23.

32. Levine DM, Landon BE, Linder JA. Trends in patient-perceived shared decision making among adults in the United States, 20022014. The Annals of Family Medicine. 2017 Nov 1;15(6):552-6.

33. Stacey D, Légaré F, Lewis K, Barry MJ, Bennett CL, Eden KB, Holmes-Rovner M, Llewellyn-Thomas H, Lyddiatt A, Thomson R, Trevena L. Decision aids for people facing health treatment or screening decisions. Cochrane database of systematic reviews. 2017(4).
34. Shay LA, Lafata JE. Where is the evidence? A systematic review of shared decision making and patient outcomes. Medical Decision Making. 2015 Jan;35(1):114-31.

35. Smith MA. The role of shared decision making in patient-centered care and orthopaedics. Orthopaedic Nursing. 2016 May 1;35(3):144-9.

How to cite this article: Narapaka PK, Katikala K, Ponnala VR et.al. Facilitators and barriers for implementation of shared decision making: a review. International Journal of Science \& Healthcare Research. 2021; 6(2): 117-122. DOI: https://doi.org/10.52403/ijshr.20210421 